\title{
Prophylactic and therapeutic approaches for human metapneumovirus
}

\author{
Prashant Kumar $^{1} \cdot$ Mansi Srivastava ${ }^{1}$
}

Received: 30 July 2018/ Accepted: 1 October 2018/Published online: 20 October 2018

(C) Indian Virological Society 2018

\begin{abstract}
Human metapneumovirus (HMPV) is an important pneumovirus which causes acute respiratory disease in human beings. The viral infection leads to mild to severe respiratory symptoms depending on the age and immune status of the infected individual. Several groups across the world are working on the development of immunogens and therapy to manage HMPV infection with promising results under laboratory conditions but till date any virus specific vaccine or therapy has not been approved for clinical use. This minireview gives an overview of the prophylactic and therapeutic approaches to manage HMPV infections.
\end{abstract}

Keywords Human metapneumovirus - Prophylactic . Therapeutic · Vaccine

\section{Introduction}

Respiratory viruses have been one of the major causes of concern among the public health authorities and scientists dealing with health issues. The threat posed by viruses like influenza A virus, respiratory syncytial virus (RSV) and severe acute respiratory syndrome (SARS) virus is well understood and variety of strategies are under development to counter these viruses. Human metapneumovirus (HMPV), which was identified in 2001 by scientists in Netherland, is yet another respiratory virus having the

Prashant Kumar

pkumar18@amity.edu

1 Amity Institute of Virology and Immunology, Amity University Uttar Pradesh, Sector-125, Noida, U.P. 201301, India ability to cause mild to severe disease in people of all age groups especially in children from 1 to 12 years of age, accounting for about $10 \%$ of all the lower respiratory tract infections (LRTIs) [3, 27, 48, 70, 78, 107]. Despite several researches, any vaccine or therapy has not yet been commercialized to take care of the HMPV infection. This review focuses on different prophylactic and therapeutic approaches that have been investigated till date against human metapneumovirus.

\section{Virus properties}

HMPV belongs to Metapneumovirus genus in the Pneumoviridae family which was created in 2016 [86]. Other members of the family include avian metapneumovirus (AMPV), human respiratory syncytial virus (HRSV), bovine respiratory syncytial virus (BRSV) and murine pneumonia virus (MPV). The enveloped virus has negative sense, single stranded, non-segmented RNA genome of length between 13,280 and 13,378 nucleotides [77]. The genome contains eight genes encoding nine proteins in the order $3^{\prime} \mathrm{N}-\mathrm{P}-\mathrm{M}-\mathrm{F}-\mathrm{M} 2-\mathrm{SH}-\mathrm{G}-\mathrm{L} \quad 5^{\prime}$ which is further flanked by a leader sequence at $3^{\prime}$ end and trailer sequence at the $5^{\prime}$ end (Fig. 1) [8, 52]. The leader and header sequence has a role in replication and transcription of the viral genome. The nucleoprotein $(\mathrm{N})$, phosphoprotein $(\mathrm{P})$, a matrix protein (M2-1) and RNA dependent RNA polymerase (L) get associated with RNA genome to form RNA polymerase complex to carry out viral replication and transcription [44]. The virion surface shows the presence of three glycoproteins viz. small hydrophobic $(\mathrm{SH})$ protein, a heavily glycosylated $\mathrm{G}$ protein and fusion (F) protein (Fig. 2). While the $G$ and $F$ proteins have a role in fusion and entry of the virus in host cell through heparan sulphate 


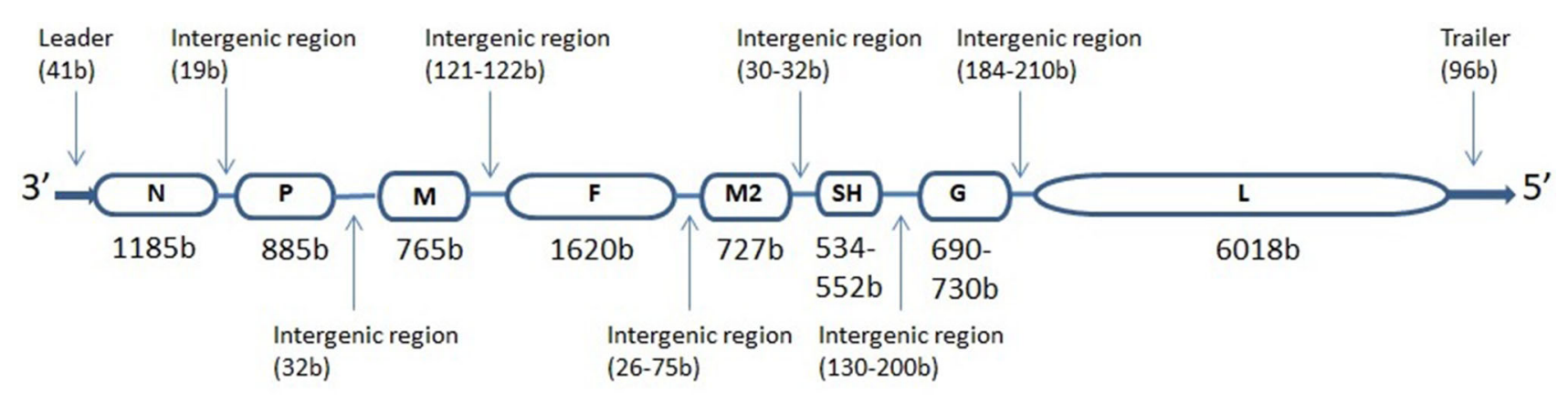

$(13.3 \mathrm{~kb})$

Fig. 1 Schematic representation of HMPV genome. Length of the genes and intergenic regions are mentioned in bracket as number of bases. Length of SH and $\mathrm{G}$ genes and most of the intergenic regions vary with the strains

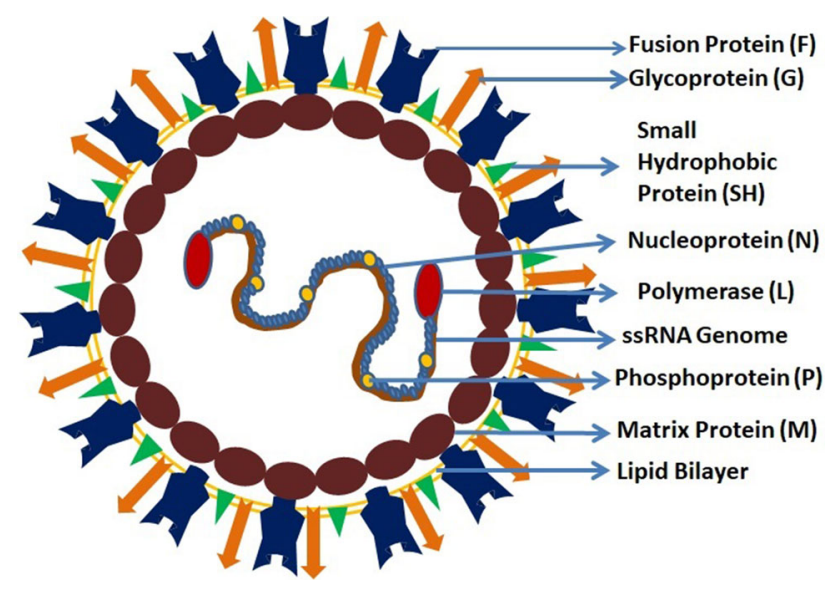

Fig. 2 Schematic representation of human metapneumovirus (HMPV). The attachment glycoprotein $(\mathrm{G})$, fusion protein $(\mathrm{F})$ and small small hydrophobic protein $(\mathrm{SH})$ of the virus protrude out on the virion surface while matrix protein $(\mathrm{M})$ lines the inner surface of lipid bilayer envelop. The nucleoprotein (N), Phosphoprotein (P) and RNA dependent RNA polymerase (L) wraps the negative sense single stranded RNA genome in the viral core and constitute the ribonucleoprotein (RNAP) complex

proteoglycan receptors, the role of $\mathrm{SH}$ protein is not completely understood but some of the studies claim that it helps the virus in evading the host antiviral immune response by down-regulating the type I IFN signalling and also has a role in regulating host membrane permeability $[41,65]$. The matrix $(\mathrm{M})$ protein forms a layer beneath the virus envelop and have a role in virus assembly and budding. Two proteins viz. M2-1 and M2-2 are encoded by the second M (M2) gene. The M2-1 protein enhances the processivity of RNA dependent RNA Polymerase (RdRP) and is required for the full length synthesis of viral mRNA [16] while the M2-2 protein maintains the balance between viral genome replication and transcription in the host cytoplasm [14, 91].

Two genotypes of HMPV have been observed in the clinical isolates reported till date: $\mathrm{A}$ and $\mathrm{B}$, which have been further divided into five genetic lineages: A1, A2a, $\mathrm{A} 2 \mathrm{~b}, \mathrm{~B} 1$ and B2. The classification has been done on the basis of variability in membrane glycoproteins of the virus. At protein level, F protein is highly conserved between the types of HMPV with the sequence identity of $94-98 \%$ while $\mathrm{G}$ protein is highly divergent with the sequence identity of only $30-35 \%$ between the subtypes $[52,110]$.

\section{Epidemiology}

HMPV has a worldwide distribution with the peak of its activity coinciding with the peak of RSV activity. Although the virus circulates throughout the year, it is predominant in late winter and spring [36, 63, 79, 93, 99, 105]. The disease severity also varies from mild respiratory symptoms to severe pneumonia which ultimately depends on other factors like age of child and presence of other chronic ailments [73, 74]. In a study done in 2017 at University Hospital of Trondheim, Norway, approximately $10 \%$ of the children hospitalized with LRTI were diagnosed with HMPV infection. It was observed that children who were born premature or had any other chronic airway disease like asthma were more prone to infection with HMPV than other related respiratory viruses like RSV. The age of child was also correlated with the disease severity. The child at the age between 12 and 23 months showed the most severe symptoms compared to other age groups and it was concluded that the maternal antibody plays a significant role in protecting a child below 6 months of age [68]. Apart from children, HMPV infection is observed in people of all age groups, though at a lower rate, with only about $3.5 \%$ of adults with LRTI being positive for HMPV infection $[49,71,81,92]$. The sero-epidemiology studies show that almost $100 \%$ of adults across the world are seropositive with respect to one or the other strain of HMPV [48, 56]. Similar observations were recorded in yet another study involving the subjects from both northern and southern 
hemisphere and it was observed that burden of HMPV was significantly higher in northern hemisphere as compared to southern hemisphere [3]. However, difference in disease severity due to strain variation is not clear and varies considerably.

\section{Immune response to $\mathrm{HMPV}$}

Knowledge of host immune response to HMPV infection is required to understand the immunopathology induced by the virus and further development of vaccines or therapeutics. Like any other virus, both innate and adaptive immune components are essential to clear the HMPV infection but it induces a weak memory response in the host [31, 38]. Innate immune responses are the first line of defence against the viral infection and act by recognizing the pathogen associated molecular patterns (PAMPS) on the viral particles through the pattern recognition receptors (PRRs) present on the immune cells in the respiratory tracts. The common PRRs like membrane bound Toll-likereceptors (TLRs), C-type lectin receptors (CLRs), cytoplasmic RIG-I like receptors (RLRs) and nucleotide-binding oligomerization domain (NOD) like receptors (NLRs) recognize the viral PAMPs and initiate the inflammatory and immune response via the cytokines produced by the cells in respiratory tract [19]. MyD88 (common adaptor of TLRs) mediated pathways has been shown to be essential for pulmonary immune response to HMPV infection by recruitment of immune cells to lungs [83]. However, HMPV $G$ protein has an important role in inhibiting the innate immune responses by targeting RIG-I in host cell cytoplasm [4, 55].

On the other hand, adaptive immunity is highly virus specific. During HMPV infection, the protective humoral immunity is mostly directed towards the $\mathrm{F}$ protein of the virus rather than $\mathrm{G}$ and $\mathrm{SH}$ proteins [35]. The cell mediated immune response is majorly responsible for immune surveillance in the infected host and clears the virus infection by activation of virus specific cytotoxic $\mathrm{T}$ lymphocytes (CTLs) which induces the apoptosis of infected cells or by activating the Th cells to further activate B cells and other immune cells like DCs and macrophages [19]. Studies done on mice models indicate that during HMPV primary infection, $\mathrm{CD}^{+}$as well as $\mathrm{CD}^{+} \mathrm{T}$ cells are responsible for inflammation and body weight loss leading to severe lung disease but they also have a protective role of clearing the virus infection from the host's body which is evident by accumulation of HMPV specific CTLs in the lungs of infected host at approximately 7 days post infection [2, 43, 54]. In the HMPV infected elderly hosts, Th2 skewing response seems to be the cause of aggravated lung diseases [25]. However, if $\mathrm{CD}^{+} \mathrm{T}$ cells are depleted, the infection is less severe and $\mathrm{CD}^{+} \mathrm{T}$ cells alone can effectively clear the virus infection [54]. Interestingly, it was also demonstrated in one of the recent study that the expression patterns of inhibitor receptor programmed death-1 (PD-1) and programmed death ligand-1 (PD-L1) during HMPV infection leads to impairment of $\mathrm{CD}^{+} \mathrm{T}$ cell response which further contributes to HMPV re-infection [33, 34, 104].

An immunocompetent host shows antiviral immune response to eliminate virus infection and the virus, on the other hand, evades the host immune response by mechanisms which are specific for the virus. Unlike RSV, HMPV doesn't have non-structural proteins and they evade the host innate immune response via their $\mathrm{G}, \mathrm{SH}$ and $\mathrm{M} 2-2$ proteins [55]. The M2-2 proteins of HMPV are specifically responsible for immune evasion by blocking the interaction between the mitochondrial antiviral signalling proteins (MAVS) and the downstream TNF receptor associated factors (TRAFs) [20].

Although sero-epidemiological studies reveal that all the individuals are infected by HMPV by the age of 5 years, repeated infection by the virus is common throughout life which may be due to diminishing immunity against the viral antigen in the host and restricted cross-reactive antibodies.

\section{Therapeutic strategies for HMPV infection}

As with most of the viral infection, only symptomatic treatment is available for HMPV infection. Several therapeutic strategies have been developed and evaluated by scientists across the world but any HMPV specific antiviral drug has not yet been brought under clinical trial.

\section{Nucleoside analogues}

Nucleoside analogues (NA) are the antimetabolites which mimic physiological nucleosides to get incorporated into newly synthesized DNA and blocks further DNA synthesis leading to chain termination. Several NAs have been assessed as antiviral agents. Ribavirin is one such NA which is effective against the pneumoviruses both in vitro and in vivo and has been used to treat the cases of HMPV infections also [21, 32, 39, 53, 108]. Apart from inhibiting the viral RNA synthesis, ribavirin modulates the host immune system by up-regulating the secretion of $\mathrm{T}$ helper (Th) 1 cytokines like TNF $\alpha$, IFN $\gamma$, IL 2 etc. by $\mathrm{CD} 4^{+}$and $\mathrm{CD}^{+} \mathrm{T}$ cells and down-regulating the secretion of $\mathrm{Th} 2$ cytokines like IL10 which further helps in restricting the viral pathogenesis $[13,89]$. In absence of any experimental proof till date, it is suggested that ribavirin may be given to treat HMPV infection by aerosol at a dose that is 
recommended for containing RSV infection [96]. However, aerosolised drugs have their own limitations like high cost, teratogenicity and potential to weaken the respiratory functions.

Ribavirin has also been used through intravenous (i.v.) route in combination with intravenous immunoglobulin (IVIg) to treat HMPV infections but the results have been quite contradictory. Dokos et al. [30] and Park et al. [75] observed that the effect of i.v. ribavirin combined with IVIg was not significant in treating the HMPV infection while few other authors have reported that i.v. ribavirin/ oral ribavirin combined with IVIg could successfully treat the infection in different category of patients $[12,50,80,95]$.

\section{Fusion inhibitors}

Fusion between viral envelop and the host cell membrane via HMPV F protein is important for the initiation of viral infection [18, 22]. Peptides capable of inhibiting this fusion event have the potential to reduce the virus replication in infected host. Deffrasnes et al. identified few peptides derived from the heptad repeat domains of HMPV F protein and assessed their effectiveness in reducing the morbidity and mortality caused by the virus. One peptide, HRA2, was found to be very effective in reducing the lung viral load, pulmonary inflammation, airway obstruction and levels of pro-inflammatory cytokines/chemokines in the treated BALB/c mice [28]. The HRA2 peptide, when expressed in Nicotiana tabacum, has been shown to inhibit the binding of virus to HEp2 cells under in vitro condition [64]. Further studies need to be done to evaluate the efficacy of the peptide expressed in plant system in inhibiting the virus infection in animal models. Recently, a fusion inhibitor, JNJ-5371867, has been reported for RSV which is another pneumovirus closely related to HMPV [87]. There is a need to search such small molecule fusion inhibitors which may have the potential to bind to HMPV F protein also in its pre-fusion conformation and prevent the virus from infecting the host cells.

\section{Sulfated sialyl lipid, NMSO3}

NMSO3, a sulfated sialyl lipid, has been shown to have potent antiviral activity against HMPV [109]. Spetch et al. assessed the effect of NMSO3 treatment on HMPV infection. Treatment of BALB/c mice with one dose of NMSO3 at $50 \mathrm{mg} \mathrm{kg}^{-1}$ body weight at the time of infection significantly reduced the lung viral load and also reduced the recruitment of inflammatory cells in the lungs. The clinical illness and level of pro-inflammatory cytokines/chemokines in the lungs was also significantly reduced under the treatment with NMSO3. It was speculated that in addition to having antiviral effect by inhibiting the viral entry and replication in host cells, NMSO3 also has anti-inflammatory effect in the recipient host [97].

\section{Interfering RNAs}

RNA interference using small interfering RNAs (siRNAs) or short hairpin RNAs (shRNAs) has been used since a long time for specific silencing of target genes. As a therapeutic approach for HMPV, Darniot et al. and Deffrasnes et al. demonstrated the efficacy of siRNAs specific for viral genes encoding nucleoprotein $(\mathrm{N})$ and phosphoprotein $(\mathrm{P})$. Darniot et al. [26] showed that the $2^{\prime}$ - $O$-methyl modified siRNA targeted to the most conserved region of HMPV nucleocapsid mRNA could partially inhibit the viral replication and confirmed that there was no off-target effect of this siRNA and also that the cytokines did not contribute in this inhibitory effect. Deffrasnes et al. [28] had previously identified two potent siRNAs (siRNA45 against $\mathrm{N}$ gene and siRNA60 against $\mathrm{P}$ gene) and demonstrated their efficacy against the strains of all four subgroups of HMPV. The G gene of HMPV was also targeted by Preston et al. but it's down-regulation did not result in reduction in viral growth, nor did any significant increase in type I interferon expression was observed.

\section{Monoclonal antibodies}

Monoclonal antibodies directed against the most conserved epitopes of the immunogenic proteins of virus have the ability to protect or minimize disease severity in infected individuals. The efficacy of prophylaxis with Palivizumab, a monoclonal antibody, has previously been shown for RSV infection in high risk groups. The fusion protein of HMPV is highly immunogenic and is conserved among various types and subtypes of the virus [24, 45, 76]. Recently, 54G10, a human monoclonal antibody directed to a conserved epitope of HMPV fusion protein, was shown to be highly neutralizing and effective in decreasing the viral titre in lungs and nasal aspirates of infected HMPV permissive mice model. The prophylactic and therapeutic efficacy of $54 \mathrm{G} 10$ was comparable to palivizumab w.r.t. viral titre in nasal aspirates and better than palivizumab w.r.t. titre in lung homogenates [94]. Prior to this, Fab DS7, a recombinant human monoclonal antibody fragment generated using phage display technology against a fusion protein epitope was evaluated and found to be significantly effective in restricting the propagation of HMPV in the lungs of cotton rats [106]. Even before this, Ulbrandt et al. [102] generated a panel of monoclonal antibodies against the $\mathrm{F}$ protein in animal models, out of which two MAbs viz. MAb 338 and MAb 234 were effective against almost all four subtypes of HMPV. It was speculated that 
humanization and optimization of the two MAbs could give a better result in human individuals. In 2005, Ma et al. [61] also generated two mouse monoclonal antibodies, 1G3 and 9B10, against $\mathrm{F}$ protein of HMPV and demonstrated their neutralizing capacity in the virus infected cells.

\section{Other prospects for development of therapeutics}

Recently, the replication and transcription of HMPV in bronchial epithelial-derived immortal cells was analyzed and it was deduced that like other filoviruses and rhabdoviruses, formation of cytoplasmic inclusion bodies is required for HMPV genome replication and transcription [69]. Understanding the mechanisms and pathways for the formation of these inclusion bodies may give a crucial lead for development of new therapeutics.

Currently, we are also working on the development of ribozyme based therapeutics which is based on the conserved nature of fusion and nucleoprotein of the virus (data not published yet).

\section{Prophylactic strategies for HMPV infection}

Vaccination is the most reliable strategy for managing any viral infection. Several efforts have been made to develop HMPV specific vaccines and most of these vaccines are directed towards the fusion protein which is the most immunogenic protein of this virus.

\section{Inactivated vaccines}

Inactivated vaccines have been very successful in managing several viral infections like influenza, polio etc. where the vaccine is stable and biologically safe. However, the efficacy of this type of vaccine varies with the virus and method used for viral inactivation significantly affects the immune response [90]. It has been demonstrated that vaccination with formalin inactivated HMPV leads to enhanced disease severity upon challenge with wild type virus which could be attributed to enhanced pulmonary histopathology and imbalanced immune response with elevated level of Th2 cytokine like IL4 [111]. Vaccination of animal models with heat inactivated HMPV has also been shown to be unsafe with enhanced level of Th2 cytokines and eosinophil infiltration in lungs of vaccinated animals [40]. The outcome of vaccination with abovementioned inactivated virus suggest for the development of better strategies to generate HMPV specific vaccines. In past few years, nanoemulsion based inactivation of virus like RSV was demonstrated to yield safe vaccines which could induce effective humoral immune response and enhanced viral clearance from the host body [59]. This strategy along with other strategies like use of $\beta$-propiolactone (BPL) and hydrogen peroxide may also be used for safer vaccine development against HMPV [90].

\section{Subunit vaccines}

Vaccination with partial or full length viral proteins rather than whole virus has been shown to be sufficient to minimize the viral pathogenesis.

\section{Viral protein expression through recombinant virus} and bacteria

Viral vectors have been the vector of choice to introduce and express recombinant proteins in targeted host. A retroviral vector expressing the HMPV $\mathrm{F}$ protein has been shown to induce strong and protective immune response against different subtypes of HMPV when given through intra-peritoneal route in mice model but this was not the case with HMPV G protein [57]. Expression of HMPV F protein via Venezuelan Equine Encephalitis virus based Viral Replicon Particle (VEE-VRP) also demonstrated high level of immunogenicity and protective efficacy against HMPV infection in African Green Monkey [5]. Likewise, recombinant Sendai virus expressing the truncated fusion protein of HMPV could induce neutralizing antibodies in cotton rats indicating the potential of such a recombinant to protect the immunized host against HMPV infection [88]. Prior to this, Tang et al. [101] successfully demonstrated the immunogenicity and protective efficacy of bovine/human chimeric parainfluenza virus type 3 expressing the HMPV F protein in African Green monkey.

Apart from the viral vector, bacterial systems have also been shown to act as carrier for viral genes. Palavecino et al. demonstrated that recombinant bacillus CalmetteGuerin (rBCG) carrying the gene encoding HMPV P protein could successfully express the viral protein and immunization with the rBCG strain could induce a protective Th1 immunity in mice model by activation of virus specific $\mathrm{T}$ cells producing IFN $\gamma$ and IL-2 [72]. This was shown to be an effective strategy to manage the HMPV infections.

\section{Purified viral protein as vaccines}

Use of soluble viral protein as vaccine can also induce the host immune response. Intramuscular injection of iscom matrix adjuvanted soluble HMPV $F$ protein in Syrian golden hamster and cynomolgus macaque model was effective in inducing cellular as well as humoral immune response against different subtypes of HMPV but for a shorter duration of time as opposed to the viral vector based vaccines [45, 46]. Prior to this, Cseke et al. [24] 
showed that a recombinant $F$ protein lacking the transmembrane domain, expressed from a DNA plasmid construct, could induce a protective immune response in cotton rats and the response was better that the full length $\mathrm{F}$ protein without any lung pathology or Th2 type response. Later on Baule et al. [7] observed the stimulation of inflammatory response by HMPV M protein and Aerts et al. [1] demonstrated the effect of $M$ protein as an adjuvant in enhancing the immunogenicity of HMPV F protein by elevating the cellular immune response. Recently, it has been shown that purified HMPV fusion protein ectodomain stabilized in its pre-fusion or post-fusion states is sufficient to induce the production of neutralizing antibodies with a capacity to neutralize the virus infectivity [6].

\section{Virus-like-particle}

Virus-like-particles (VLPs) have been successfully used as vaccine candidates against some important viral pathogens like human papilloma virus and rota virus. The nonpathogenic nature and ability of the VLPs to expose the viral proteins in their native conformation makes it one of the best vaccination strategies. A HMPV VLP was developed by Cox et al. [23] by expressing the HMPV fusion and matrix protein in suspension adapted HEK293 cells and a protective immune response could be generated in mice model without any Th2 skewed cytokine response. The VLP not only induced the antibody response but also cell mediated immune response against the HMPV F protein and the immunogenicity was enhanced by adjuvants like TiterMax Gold or $\alpha$-galactosylceramide. Prior to this, Levy et al. developed a HMPV VLP with retroviral core and HMPV surface proteins ( $F \& G$ ) and demonstrated its efficacy in activating the protective humoral immune response against homologous as well as heterologous strains of HMPV in mice model [57]. The observations suggest that the F protein based VLPs can be a potent vaccine candidate to deal with the HMPV infections.

\section{Live attenuated viruses}

Live attenuated viruses are the live particles designed to provide protective immunity to vaccine recipients against specific viruses. These vaccines include viruses which are weakened enough to lose their virulence, maintaining their structural integrity so that its infection mimics the natural infection allowing the host immune system to recognize the virus as a whole but without causing any disease. These viruses, as a vaccine, activate both cellular as well humoral immunity and doesn't require any booster dose. Though this type of vaccine has proven to be highly significant in eradicating some viral diseases but safety issues and efficacy is a matter of great concern in case of many viral infections [67].

These vaccines may be recombinant or non-recombinant. Non-recombinant live attenuated viral vaccines are generated by virus culture under altered conditions when viral genome incorporates several mutations which make the virus avirulent under normal host physiological conditions. These altered conditions include low temperature conditions and chemical treatments [17, 37, 62]. Though these non-recombinant attenuated viruses activate the immune system efficiently but they may tend to revert back to virulent viruses inside the host causing serious disease [113]. On the other hand, recombinant live attenuated viruses are generated by using reverse genetic techniques where the virulence factor is either eliminated or modified irreversibly [98]. Sufficient attenuation is must for a successful live attenuated viral vaccine.

Non-recombinant cold adapted HMPV viral vaccine was developed and shown to be protective against the viral infection in hamster model [47]. Several attempts have also been made to generate recombinant HMPV by transfecting the cultured animal cells with viral cDNA and plasmids encoding the virus specific RdRP [9]. The generation of attenuated HMPV could be achieved by deleting the genes encoding G, SH, M2-2 or P protein [11]. The replication of virus lacking $\mathrm{G}$ protein was reduced by $\sim 40$-fold while that of virus lacking both $\mathrm{G}$ and $\mathrm{SH}$ protein was reduced by $\sim 600$-fold as compared to the wild type HMPV in rodent models [10]. Maximum attenuation was achieved by the deletion of M2-2 gene and the attenuated virus could induce protective immunity in African green monkey model [11]. A modification in M2-1 gene of HMPV by substituting third cysteine and last histidine in the zinc binding motif also attenuates the virus and the attenuated virus has the ability to induce protective immune response in cotton rats [15]. Mutation in $S$-adenosylmethionine binding motif of $\mathrm{L}$ protein and removal of $\mathrm{N}$-linked carbohydrate in fusion protein also attenuates the virus and the attenuated virus provides protection to homologous as well as heterologous strains of HMPV [60, 112]. Attenuation could also be attained by replacing the HMPV $\mathrm{P}$ protein with $\mathrm{P}$ protein of avian MPV and it was demonstrated that the recombinant virus having avian MPV P protein replicated very poorly in healthy adults but the mechanism is yet to be understood [51]. In 2013, a wild type recombinant HMPV having codon optimised SH protein was approved to be used as parent virus for the development of live attenuated HMPV specific vaccine candidate [100]. Recently, Ren et al. discussed the significance of M2-2 protein based live attenuated vaccine candidate which can not only induce cellular immune response via the CTL epitope but also suppress HMPV induced host innate immunity and regulate the expression of miRNAs 
responsible for immune related gene expressions [29, 82, 84, 85]. With these strategies under development, there is a need for the validation of an efficient vaccine candidate through clinical trials.

\section{Epitope based vaccine}

For the development of a successful vaccination strategy, it is necessary to identify the viral components required to stimulate the cellular and humoral immune response. Host's adaptive immune response is targeted to either B cell or $\mathrm{T}$ cell epitope on a viral pathogen. Several studies have been done to identify the immunogenic epitopes of HMPV [66, 94, 103]. Herd et al. [42] identified major histocompatibility class I restricted CTL epitopes on $\mathrm{N}, \mathrm{G}$, M2-2 and SH protein of HMPV and demonstrated that administration of these epitopes as peptide vaccine elicits effector and memory CTL responses along with enhanced expression of Th1 type cytokine (IFN $\gamma$ and IL12) and significantly low level of Th2 type cytokine response (IL10 and IL4) response resulting in reduced viral load and immunopathology in lungs of mice model. Recently, a HMPV specific multi-epitope peptide was designed and evaluated for its protective efficacy in mice model. Six B cell epitope, four CTL epitope and two Th cell epitope of HMPV were predicted and linked using defined spacer sequences to design the multi-epitope peptide (MEP) which was expressed in bacterial system. It was shown that vaccination with adjuvanted MEP could induce strong humoral as well as cell mediated immune response in $\mathrm{BALB} / \mathrm{c}$ mice and the serum of treated mice had the capacity to neutralize the HMPV infection in vitro [58].

\section{Concluding remarks}

Human metapneumovirus is an important respiratory pathogen having the capacity to cause serious and fatal disease in human beings. It has been easier to characterize this virus because of its similarity to another important respiratory virus, RSV. The approaches to manage the HMPV infection have also been quite similar to that RSV. Though common antivirals like ribavirin and IVIg are available, yet HMPV specific therapeutic approaches are necessary to effectively challenge the fatal cases. Palivizumab, the monoclonal antibody generated against RSV, is effective against HMPV also, yet HMPV specific monoclonal antibodies like 54G10 and Fab-DS7 have been developed and successfully tested in animal models. If tested and commercialized like Palivizumab, these monoclonal antibodies may prove to be a boon for HMPV infected individuals showing serious symptoms. Most of the therapies against HMPV are targeted to fusion protein owing to its conserved nature among various types and subtypes of the virus. Certain peptide based fusion inhibitors like HRA2 has been tested and found to be protective against HMPV. Likewise, siRNAs targeted to the conserved regions of genes encoding nucleoprotein and phosphoprotein of HMPV has also shown protective effects against the viral infection. Among chemical inhibitors, a sulphated sialyl lipid, $\mathrm{NMSO}_{3}$, has been shown not only to decrease the viral titre in infected individuals but it also modulates the host immune system by its anti-inflammatory effect. All the therapeutic approaches developed till date is under research but it's important that an effective therapy gets approved and made available for use by the patient's so that the morbidity and mortality due to HMPV infection is minimized.

Prophylaxis has always been better than therapy, and vaccination is the best approach to control or eliminate any pathogen from any population. HMPV, being a RNA virus, is highly prone to mutation and development of an effective vaccine candidate is a challenge, yet research on the development of a universal vaccine candidate is underway. Inactivated vaccine candidates against HMPV have not yet been successfully tested in animal models with most of them leading to enhanced disease severity upon subsequent natural infection. On the other hand, vaccination with subunit vaccine composed either of purified HMPV fusion protein or the fusion protein expressed via different viral or bacterial vectors viz. retroviral vector, alphavirus vector, rBCG etc. could induce protective immunity against both homologous as well as heterologous strains of the virus, though for a short duration. Fusion protein based VLPs in combination with certain adjuvants like TiterMax Gold are also highly immunogenic and protective against the virus. Though the inactivated or subunit vaccines are safe but the requirement of booster doses and lack of strong cellular immune response poses a limitation on its use. The live attenuated viruses overcome this limitation. Recombinant approach to develop live attenuated viral vaccine candidate through reverse genetics technique can be considered as one of the best approach, provided a good level of attenuation is attained and immunogenicity is maintained. Attempts to generate live attenuated HMPV vaccine candidates have been successful with good protective efficacy in rodents and non-human primates but none of them have yet entered the clinical trials. However, it can be said that though HMPV was discovered late, significant advances have been made to intervene the viral infection.

\section{Compliance with ethical standards}

Conflict of interest There are no conflicts of interest. 


\section{References}

1. Aerts L, Rheaume C, Carbonneau J, Lavigne S, Couture C, Hamelin ME, et al. Adjuvant effect of the human metapneumovirus (HMPV) matrix protein in HMPV subunit vaccines. J Gen Virol. 2015;96:767-74.

2. Alvarez R, Tripp RA. The immune response to human metapneumovirus is associated with aberrant immunity and impaired virus clearance in BALB/c mice. J Virol. 2005;79:5971-8.

3. Anderson EJ, Simoes AF, Buttery JP, Dennehy PH, Domachowske JB, Jensen K, et al. Prevalence and characteristics of human metapneumovirus infection among hospitalized children at high risk for severe lower respiratory tract infection. J Pediatric Infect Dis Soc. 2012;1:212-22.

4. Bao X, Liu T, Shan Y, Li K, Garofalo RP, Casola A. Human metapneumovirus glycoprotein $\mathrm{G}$ inhibits innate immune response. PLoS Pathogen. 2008;4(5):e1000077.

5. Bates JT, Pickens JA, Schuster JE, Johnson M, Tollefson SJ, Williams JV, et al. Immunogenicity and efficacy of alphavirusderived replicon vaccines for respiratory syncytial virus and human metapneumovirus in non-human primates. Vaccines. 2016;34(7):950-6.

6. Battles MB, Mas V, Olmedillas E, Lano O, Vazquez M, Rodriguez L, et al. Structure and immunogenicity of pre-fusionstabilized human metapneumovirus F glycoprotein. Nat Commun. 2017;8:1528.

7. Baule AB, Reynard O, Perret M, Berland JL, Maache M, Peyrefitte $\mathrm{C}$, et al. The human metapneumovirus matrix protein stimulates the inflammatory immune response in vitro. PLoS ONE. 2011;6(3):e17818.

8. Biacchesi S, Skiadopoulos MH, Boivin G, Hanson CT, Murphy BR, Collins PL, et al. Genetic diversity between human metapneumovirus subgroups. Virology. 2003;315:1-9.

9. Biacchesi S, Skiadopoulos MH, Tran KC, Murphy BR, Collins PL, Buchholz UJ. Recovery of human metapneumovirus from cDNA: optimization of growth in vitro and expression of additional genes. Virology. 2004;321:247-59.

10. Biacchesi S, Skiadopoulos MH, Yang L, Lamirande EW, Tran $\mathrm{KC}$, Murphy BR, et al. Recombinant human metapneumovirus lacking the small hydrophobic SH and/or attachment G protein: deletion of $\mathrm{G}$ yields a promising candidate. $\mathrm{J}$ Virol. 2004;78:12877-87.

11. Biacchesi S, Pham QN, Skiadopoulos MH, Murphy BR, Collins PL, Buchholz UJ. Infection of nonhuman primates with recombinant human metapneumovirus lacking the $\mathrm{SH}, \mathrm{G}$ or $\mathrm{M}-2$ protein categories each as nonessential accessory protein and identifies vaccine candidates. J Virol. 2005;79(19):12608-13.

12. Bonney D, Razali H, Turner A, Will A. Successful treatment of human metapneumovirus pneumonia using combination therapy with intravenous ribavirin and immune globulin. Br J Haematol. 2009; 145:665-78.

13. Brooks DG, Mc Gavern DB, Oldstone MBA. Reprogramming of antiviral $\mathrm{T}$ cell prevents inactivation and restores $\mathrm{T}$ cell activity during persistent viral infection. J Clin Invest. 2006;116(6):1675-85.

14. Buchholz UJ, Biacchesi S, Pham QN, Tran KC, Yong L, Luongo $\mathrm{CL}$, et al. Deletion of M2 gene open reading frames 1 and 2 of human metapneumovirus: effects on RNA synthesis, attenuation and immunogenicity. J Virol. 2005;79(11):6588-97.

15. Cai H, Zhang Y, Ma Y, Sun J, Liang X, Li J. Zinc binding activity of human metapneumovirus M-2 protein is indispensable for viral replication and pathogenesis in vivo. J Virol. 2015;89(12):6391-405.

16. Cai H, Zhang Y, Lu M, Liang X, Jennings R, Niewiesk S, et al. Phosphorylation of human metapneumovirus M2-1 protein upregulates viral replication and pathogenesis. J Virol. 2016;90(16):7323-38.

17. Caplen H, Peters CJ, Bishop DHL. Mutagen-directed attenuation of rift valley fever virus as a method for vaccine development. J Gen Virol. 1985;66:2271-7.

18. Chang A, Masante C, Buchholz UJ, Dutch RE. Human metapneumovirus (HMPV) binding and infection are mediated by interaction between the HMPV fusion protein and heparin sulphate. J Virol. 2012;86(6):3230-43.

19. Cheemarla NR, Plata AG. Immune response to human metapneumovirus infection: what we have learned from mouse model. Pathogens. 2015;4:682-96.

20. Chen Y, Deng X, Deng J, Zhou J, Ren Y, Liu S, et al. Functional motifs responsible for human metapneumovirus M2-2- mediated innate immune evasion. Virology. 2016;499:361-8.

21. Chu HY, Renaud C, Ficken E, Thomson B, Kuypers J, Englund JA. Respiratory tract infections due to human metapneumovirus in immunocompromised children. J Pediatric Infect Dis Soc. 2014;3(4):286-93.

22. Cox RG, Livesay SB, Johnson M, Ohi MD, Williams JV. The human metapneumovirus fusion protein mediates entry via an interaction with RGD-binding integrins. $\mathrm{J}$ Virol. 2012;86(22):12148-60.

23. Cox RG, Erickson JJ, Hastings AK, Becker JC, Johnson M, Craven RE, et al. Human metapneumovirus virus-like particle induces protective $\mathrm{B}$ and $\mathrm{T}$ cell responses in a mouse model. J Virol. 2014;88(11):6368-79.

24. Cseke G, Wright DW, Tollefson SJ, Johnson JE, Crowe JE Jr, Williams JV. Human metapneumovirus fusion protein vaccines that are immunogenic and protective in cotton rats. J Virol. 2007;81(2):698-707.

25. Darniot M, Pitoiset C, Petrella T, Aho S, Pothier P, Manoha C. Age-associated aggrevation of clinical disease after primary metapneumovirus infection of BALB/c mice. $\mathrm{J}$ Virol. 2009;83(7):3323-32.

26. Darniot M, Schildgen V, Schildgen O, Sproat B, Kleines M, Ditt $\mathrm{V}$, et al. RNA interference in vitro and in vivo using Dsi RNA targeting the nucleocapsid $\mathrm{N}$ mRNA of human metapneumovirus. Antiviral Res. 2012;93:364-73.

27. Davis CR, Stockmann C, Pavia AT, Byington CL, Blaschke AJ, Hersh AL, et al. Incidence, morbidity and costs of humanmetapneumovirus infection in hospitalized children. J Pediatric Infect Dis Soc. 2016;5(3):303-11.

28. Deffrasnes C, Hamelin ME, Prince GA, Boivin G. Identification and evaluation of highly effective fusion inhibitor for human metapneumovirus. Antimicrob Agents Chemother. 2008;52(1):279-87.

29. Deng J, Ptashkin RN, Wang Q, Liu G, Zhang G, Lee I, et al. Human metapneumovirus infection induces significant changes in small noncoding RNA expression in airway epithelial cells. Mol Ther. 2014;3:e163.

30. Dokos C, Masjosthusmann K, Rellensmann G, Werner C, Schuler-Luttmann S, Muller KM, et al. Fatal human metapneumovirus infection following allogeneic hematopoietic stem cell transplantation. Transpl Infect Dis. 2013;15:E97-101.

31. Douville RN, Bastien N, Li Y, Pochard P, Simons FER, HayGlass KT. Human metapneumovirus elicits weak IFN- $\gamma$ memory responses compared with respiratory syncytial virus. J Immunol. 2006; 176:5848-55.

32. Egli A, Bucher C, Dumoulin A, Stern M, Buser A, Bubendorf L, et al. Human metapneumovirus infection after allogeneic hematopoietic stem cell transplantation. Infection. 2012;40:677-84.

33. Erickson JJ, Gilchuk P, Hastings AK, Tollefson SJ, Johnson M, Downing $\mathrm{MB}$, et al. Viral acute lower respiratory infections 
impair $\mathrm{CD}^{+} \mathrm{T}$ cells through PD-1. Clin Invest. 2012;122(8):2967-82.

34. Erickson JJ, Rogers MC, Hastings AK, Tollefson SJ, Williams JV. PD-1 impairs secondary effector lung $\mathrm{CD} 8^{+} \mathrm{T}$ cells during respiratory virus reinfection. J Immunol. 2014;193:5108-17.

35. Falsey AR, Hennessey PA, Formica MA, Criddle MM, Biear JM, Walsh EE. Humoral immunity to human metapneumovirus infection in adults. Vaccine. 2010;28:1477-80.

36. Gerna G, Campanini G, Rovida F, Sarasini A, Lilleri D, Paolucci S, et al. Changing circulation rate of human metapneumovirus strains and types among hospitalized pediatric patients during three consecutive winter-spring seasons. Arch Virol. 2005; 150:2365-75.

37. Glezen WP. Cold-adapted, live attenuated influenza vaccine. Expert Rev Vaccines. 2004;3:131-9.

38. Gonzalez AE, Lay MK, Jara EL, Espinoza JA, Gomez RS, Soto $\mathrm{J}$, et al. Aberrant $\mathrm{T}$ cell immunity triggered by human respiratory syncytial virus and human metapneumovirus infection. Virulence. 2017;8:685-704.

39. Hamelin M, Prince GA, Boivin G. Effect of ribavirin and glucocorticoid treatment in a mouse model of human metapneumovirus infection. Antimicrob Agents Chemother. 2006;50:774-7.

40. Hamelin M, Couture C, Sackett MK, Boivin G. Enhanced lung disease and $\mathrm{Th} 2$ response following human metapneumovirus infection in mice immunized with the inactivated virus. J Gen Virol. 2007;88:3391-400.

41. Hastings AK, Amato KR, Wen SC, Peterson LS, Williams JV. Human metapneumovirus small hydrophobic $(\mathrm{SH})$ protein downregulates type I IFN pathway signaling by affecting STAT1 expression and phosphorylation. Virology. 2016;494:248-56.

42. Herd KA, Mahalingam S, Mackay IM, Nissen IM, Sloots TP, Tindle RW. Cytotoxic T-lymphocyte epitope vaccination protects against human metapneumovirus infection and disease in mice. J Virol. 2006;80:2034-44.

43. Herd KA, Nelson M, Mahalingam S, Tindle RW. Pulmonary infection of mice with human metapneumovirus induces local cytotoxic $\mathrm{T}$-cell and immunoregulatory cytokine responses similar to those seen with human respiratory syncytial virus. J Gen Virol. 2010;91:1302-10.

44. Herfst S, de Graaf M, Schickli JH, Tang RS, Kaur J, Yang C, et al. Recovery of human metapneumovirus genetic lineages A and B from cloned cDNA. J Virol. 2004;78:8264-70.

45. Herfst S, de Graaf M, Schrauwen EJA, Ulbrandt ND, Barnes AS, Senthil K, et al. Immunization of Syrian golden hamsters with $F$ subunit vaccine of human metapneumovirus induces protection against challenge with homologous or heterologous strains. J Gen Virol. 2007;88:2702-9.

46. Herfst S, Schrauwen EJA, de Graaf M, Amerongen G, Hoogen BG, de Swart RL, et al. Immunogenicity and efficacy of two candidate human metapneumovirus vaccines in cynomolgus macaques. Vaccine. 2008;26:4224-30.

47. Herfst S, de Graaf M, Schrauwen EJA, Sprong L, Hussain K, Hoogen BG, et al. Generation of temperature-sensitive human metapneumovirus strains that provide protective immunity in hamsters. J Gen Virol. 2008;89:1553-62.

48. Hoogen BG, Bestebroer TM, Osterhaus ADME, Fouchier RAM. Analysis of the genomic sequence of a human metapneumovirus. Virology. 2002;295:119-32.

49. Kahn JS. Epidemiology of human metapneumovirus. Clin Microbiol Rev. 2006;19:546-57.

50. Kamble RT, Bollard C, Demmler G, LaSala PR, Carrum G. Human metapneumovirus infection in a hematopoietic transplant recipient. Bone Marrow Transplant. 2007;40:699-700.
51. Karron RA, Mateo JS, Wanionek K, Collins PL, Buchholz UJ. Evaluation of a live attenuated human metapneumovirus vaccine in adults and children. J Pediatric Infect Dis Soc. 2017;00:1-4.

52. Kim JI, Park S, Lee I, Park KS, Kwak EJ, Moon KM, et al. Genome-wide analysis of human metapneumovirus evolution. PLoS ONE. 2016;11:e0152962.

53. Kitanovski L, Kopriva S, Pokorn M, Dolnicar MB, Rajic V, Stefanovic M, et al. Treatment of severe human metapneumovirus (hMPV) pneumonia in an immunocompromised child with oral ribavirin and IVIG. J Pediatr Hematol Oncol. 2013;35:e311-3.

54. Kolli D, Bataki EL, Spetch L, Guerrero-Plata A, Jewell AM, Piedra PA, et al. T lymphocytes contribute to antiviral immunity and pathogenesis in experimental human metapneumovirus infection. J Virol. 2008;82:8560-9.

55. Kolli D, Bao X, Casola A. Human metapneumovirus antagonism of innate immune responses. Viruses. 2012;4:3551-71.

56. Leung J, Esper F, Weibel C, Kahn JS. Seroepidemiology of human metapneumovirus (hMPV) on the basis of a novel enzyme-linked immunosorbent assay utilizing hMPV fusion protein expressed in recombinant vesicular stomatitis virus. J Clin Microbiol. 2005;43:1213-9.

57. Lévy C, Aerts L, Hamelin M, Granier C, Szécsi J, Lavillette D, et al. Virus-like particle vaccine induces cross-protection against human metapneumovirus infections in mice. Vaccine. 2013;31:2778-85.

58. Li X, Guo L, Kong M, Su X, Yang D, Zou M, et al. Design and evaluation of a multi-epitope peptide of human metapneumovirus. Intervirology. 2015;58:403-12.

59. Lindell DM, Morris SB, White MP, Kallal LE, Lundy PK, et al. A novel inactivated intranasal respiratory syncytial virus vaccine promotes viral clearance without Th2 associated vaccineenhanced disease. PLoS ONE. 2011;6:e21823.

60. Liu P, Shu Z, Qin X, Dou Y, Zhao Y, Zhao X. A live attenuated human metapneumovirus vaccine strain provides complete protection against homologous viral infection and cross-protection against heterologous viral infection in $\mathrm{BALB} / \mathrm{c}$ mice. Clin Vaccine Immunol. 2013;20:1246-54.

61. Ma X, Endo R, Ebihara T, Ishiguro N, Ishiko H, Kikuta H. Production and characterization of neutralizing monoclonal antibodies against human metapneumovirus $\mathrm{F}$ protein. Hybridoma. 2005;24:201-5.

62. Maassab HF, Bryant ML. The development of live attenuated cold-adapted influenza virus vaccine for humans. Rev Med Virol. 1999;9:237-44.

63. Mahalingam S, Schwarze J, Zaid A, Nissen M, Sloots T, Tauro S. Perspective on the host response to human metapneumovirus infection: what can we learn from respiratory syncytial virus infections? Microbes Infect. 2006;8:285-93.

64. Márquez-Escobar VA, Tirado-Mendoza R, Noyola DE, Gutiérrez-Ortega A, Alpuche-Solís AG. HRA2pl peptide: a fusion inhibitor for human metapneumovirus produced in tobacco plants by transient transformation. Planta. 2015. https://doi.org/ 10.1007/s00425-015-2277-5.

65. Masante C, Najjar FE, Chang A, Jones A, Moncman CL, Dutch RE. The human metapneumovirus small hydrophobic protein has properties consistent with those of a viroporin and can modulate viral fusogenic activity. J Virol. 2014;88:6423-33.

66. Melendi GA, Zavala F, Buchholz UJ, Boivin G, Collins PL, Kleeberger SR, et al. Mapping and characterization of the primary and anamnestic $\mathrm{H}$-2d-restricted cytotoxic T-lymphocyte response in mice against human metapneumovirus. J Virol. 2007;81:11461-7.

67. Minor PD. Live attenuated vaccines: historical successes and current challenges. Virology. 2015;479:379-92. 
68. Moe N, Krokstad S, Stenseng IH, Christensen A, Skanke LH, Risnes KR, et al. Comparing human metapneumovirus and respiratory syncytial virus: viral co-detections, genotypes and risk factors for severe disease. PLoS ONE. 2017;12:e0170200.

69. Munoz NC, Branttie J, Slaughter KB, Dutch RE. Human metapneumovirus induces formation of inclusion bodies for efficient genome replication and transcription. $\mathrm{J}$ Virol. 2017;91(24):e01282-17.

70. Nandhini G, Sujatha S, Jain N, Dhodapkar R, Tamilarasu K, Krishnamurthy S, et al. Prevalence of Human metapneumovirus infection among patients with influenza-like illness: report from a Tertiary Care Centre, Southern India. Indian J Med Microbiol. 2016;34:27-32.

71. Owor BE, Masankwa GN, Mwango LC, Njeru RW, Agoti CN, Nokes DJ. Human metapneumovirus epidemiological and evolutionary patterns in Coastal Kenya, 2007-11. BMC Infect Dis. 2016;16:301-11.

72. Palavecino CE, Cespedes PF, Gomez RS, Kalergis AM, Bneno SM. Immunization with recombinant bacillus Calmette-Guerin strain confers protective Th1 immunity against the human metapneumovirus. J Immunol. 2014;192:214-23.

73. Pancham K, Sami I, Perez GF, Huseni S, Kurdi B, Rose MC, et al. Human metapneumovirus infection is associated with severe respiratory disease in preschool children with history of prematurity. Pediatr Neonatol. 2016;57:27-34.

74. Papenburg J, Hamelin M, Ouhoummane N, Carbonneau J, Ouakki M, Raymond F, et al. Comparison of risk factors for human metapneumovirus and respiratory syncytial virus disease severity in young children. J Infect Dis. 2012;206:178-89.

75. Park S, Baek S, Lee S, Choi S, Kim YS, Woo JH, et al. Efficacy of oral ribavirin in hematologic disease patients with paramyxovirus infection: analytic strategy using propensity scores. Antimicrob Agents Chemother. 2013;57:983-9.

76. Peret TCT, Boivin G, Li Y, Couillard M, Humphrey C, Osterhaus ADME, et al. Characterization of human metapneumoviruses isolated from patients in North America. J Infect Dis. 2002;185:1660-3.

77. Piyaratna R, Tollefson SJ, Williams JV. Genomic analysis of four human metapneumovirus prototypes. Virus Res. 2011;160:200-5.

78. Principi N, Esposito S. Paediatric human metapneumovirus infection: epidemiology, prevention and therapy. J Clin Virol. 2014;59:141-7.

79. Rafiefard F, Yun Z, Orvell C. Epidemiologic characteristics and seasonal distribution of human metapneumovirus infections in five epidemic seasons in Stockholm, Sweden, 2002-2006. J Med Virol. 2008;80:1631-8.

80. Raza K, Ismailjee SB, Crespo M, Studer SM, Sanghavi S, Paterson DL, et al. Successful outcome of human metapneumovirus (hMPV) pneumonia in a lung transplant recipient treated with intravenous ribavirin. J Heart Lung Transplant. 2007;26:862-4.

81. Reiche J, Jacobsen S, Neubauer K, Hafemann S, Nitsche A, et al. Human metapneumovirus: insights from a ten-year molecular and epidemiological analysis in Germany. PLoS ONE. 2014;9:e88342.

82. Ren J, Wang Q, Kolli D, Prusak DJ, Tseng CK, Chen ZJ, et al. Human metapneumovirus M2-2 protein inhibits innate cellular signaling by targeting MAVS. J Virol. 2012;86:13049-61.

83. Ren J, Kolli D, Deng J, Fang R, Gong B, Xue M, et al. MyD88 controls human metapneumovirus-induced pulmonary immune responses and disease pathogenesis. Virus Res. 2013. https://doi. org/10.1016/j.virusres.2013.06.014.

84. Ren J, Liu G, Go J, Kolli D, Zhang G, et al. Human metapneumovirus M2-2 protein inhibits innate immune response in monocyte-derived dendritic cells. PLoS ONE. 2014;9:e91865.
85. Ren J, Phan T, Bao X. Recent vaccine development for human metapneumovirus. J Gen Virol. 2015;96:1515-20.

86. Rima B, Collins P, Easton A, Fouchier R, Kurath G, Lamb RA, et al. ICTV virus taxonomy profile: pneumoviridae. J Gen Virol. 2017;98:2912-3.

87. Roymans D, Alnajjar SS, Battles MB, Sitthicharoenchai P, Furmanova-Hollenstein P, Rigaux P, et al. Therapeutic efficacy of a respiratory syncytial virus fusion inhibitor. Nat Commun. 2017;8:167-81.

88. Russell CJ, Jones BG, Sealy RE, Surman SL, Mason JL, Hayden $\mathrm{RT}$, et al. A Sendai virus recombinant vaccine expressing a gene for truncated human metapneumovirus (hMPV) fusion protein protects cotton rats from hMPV challenge. Virology. 2017;509:60-6.

89. Safdar A. Immune modulatory activity of ribavirin for serious human metapneumovirus disease: early i.v. therapy may improve outcomes in immunosuppressed SCT recipients. Bone Marrow Transplant. 2008;41:707-8.

90. Sanders B, Koldijk M, Schuitemaker H. Inactivated viral vaccines, chapter 2. In: Nunnally BK, et al., editors. Vaccine analysis: strategies, principles, and control. Dordrecht: Springer; 2015. p. 45-80.

91. Schickli JH, Kaur J, MacPhail M, Guzzetta JM, Spaete RR, Tang RS, et al. Deletion of human metapneumovirus M2-2 increases mutation frequency and attenuates growth in hamsters. Virol J. 2008;5:69-82.

92. Schildgen V, van den Hoogen B, Fouchier R, Tripp RA, Alvarez R, Manoha C. Human metapneumovirus: lessons learned over the first decade. Clin Microbiol Rev. 2011;24(4):734-54.

93. Schuster JE, Khuri-Bulos N, Faouri S, Shehabi A, Johnson M, Wang L. Human metapneumovirus infection in Jordanian children: epidemiology and risk factors for severe disease. Pediatr Infect Dis J. 2015;34(12):1335-41.

94. Schuster JE, Cox RG, Hastings AK, Boyd KL, Wadia J, Chen Z, et al. A broadly neutralizing human monoclonal antibody exhibits in vivo efficacy against both human metapneumovirus and respiratory syncytial virus. J Infect Dis. 2015;211:216-25.

95. Shachor-Meyouhas Y, Kassis I, Ben-Barak A. Treatment with oral ribavirin and IVIG of severe human metapneumovirus pneumonia (HMPV) in immune compromised child. Pediatr Blood Cancer. 2011;57:350-1.

96. Shahda S, Carlos WG, Kiel PJ, Khan BA, Hage CA. The human metapneumovirus: a case series and review of the literature. Transpl Infect Dis. 2011;13(3):324-8.

97. Spetch L, Bowlin TL, Casola A. Effect of NMSO3 treatment in a murine model of human metapneumovirus infection. J Gen Virol. 2008;89:2709-12.

98. Stobart CC, Moore ML. RNA virus reverse genetics and vaccine design. Viruses. 2014;6:2531-50.

99. Stockton J, Stephenson I, Fleming D, Zambon M. Human metapneumovirus as a cause of community-acquired respiratory illness. Emerg Infect Dis. 2002;8(9):897-901.

100. Talaat KR, Karron RA, Thumar B, McMahon BA, Schmidt AC, Collins PL, et al. Experimental infection of adults with recombinant wild-type human metapneumovirus. J Infect Dis. 2013;208:1669-78.

101. Tang RS, Mahmood K, MacPhail M, Guzzetta JM, Haller AA, Liu $\mathrm{H}$, et al. A host-range restricted parainfluenza virus type 3 (PIV3) expressing the human metapneumovirus (hMPV) fusion protein elicits protective immunity in African green monkeys. Vaccine. 2005;23:1657-67.

102. Ulbrandt ND, Ji H, Patel NK, Riggs JM, Brewah YA, Ready S, et al. Isolation and characterization of monoclonal antibodies which neutralize human metapneumovirus in vitro and in vivo. J Virol. 2006;80(16):7799-806. 
103. Ulbrandt ND, Ji H, Patel NK, Barnes AS, Wilson S, Kiener PA, et al. Identification of antibody neutralization epitopes on the fusion protein of human metapneumovirus. J Gen Virol. 2008;89:3113-8.

104. Wen SC, Schuster JE, Gilchuk P, Boyd KL, Joyce S, Williams JV. Lung CD8T cell impairment occurs during human metapneumovirus infection despite virus-like particle induction of functional CD8T cells. J Virol. 2015;89:8713-26.

105. Williams JV, Harris PA, Tollefson SJ, Halburnt-Rush LL, Pingsterhaus JM, Edwards KM, et al. Human metapneumovirus and lower respiratory tract disease in otherwise healthy infants and children. N Engl J Med. 2004;350:443-50.

106. Williams JV, Chen Z, Cseke G, Wright DW, Keefer CJ, Tollefson SJ, et al. A recombinant human monoclonal antibody to human metapneumovirus fusion protein that neutralizes virus in vitro and is effective therapeutically in vivo. $\mathrm{J}$ Virol. 2007;81(15):8315-24.

107. Williams JV, Edwards KM, Weinberg GA, Griffin MR, Hall $\mathrm{CB}, \mathrm{Zhu} \mathrm{Y}$, et al. Population-based incidence of human metapneumovirus in hospitalized children. Infect Dis. 2010;201(12):1890-8.

108. Wyde PR, Chetty SN, Jewell AM, Boivin G, Piedra PA. Comparison of the inhibition of human metapneumovirus and respiratory syncytial virus by ribavirin and immune serum globulin in vitro. Antiviral Res. 2003;60:51-9.

109. Wyde PR, Moylett EH, Chetty SN, Jewell A, Bowlin TL, Piedra PA. Comparison of the inhibition of human metapneumovirus and respiratory syncytial virus by $\mathrm{NMSO} 3$ in tissue culture assays. Antiviral Res. 2004;63:51-9.

110. Yang C, Wang CK, Tollefson SJ, Piyaratna R, Lintao LD, Chu $\mathrm{M}$, et al. Genetic diversity and evolution of human metapneumovirus fusion protein over twenty years. Virol J. 2009;6:138-47.

111. Yim KC, Cragin RP, Boukhvalova MS, Blanco JCG, Hamlin M, Boivin G, Porter DD, Prince GA. Human metapneumovirus: enhanced pulmonary disease in cotton rats immunized with formalin-inactivated virus vaccine and challenged. Vaccine. 2007;25(27):5034-40.

112. Zhang Y, Wei Y, Zhang X, Cai H, Niewiesk S, Li J. Rational design of human metapneumovirus live attenuated vaccine candidates by inhibiting viral mRNA cap methyltransferase. J Virol. 2014;88(19):11411-29.

113. Zhou B, Meliopoulos VA, Wang W, Lin X, Stucker KM, Halpin RA, et al. Reversion of cold-adapted live attenuated influenza vaccine into a pathogenic virus. J Virol. 2016;90:8454-63. 